\title{
MATERIAL DEPRIVATION AND CONSUMPTION
}

\author{
Basak Kus *, Brian Nolan ** and Christopher T. Whelan ***
}

*Department of Sociology, Wesleyan University, ** College of Human Sciences, University College Dublin *** School of Sociology \& Social Policy, Queen's University Belfast \& School of Sociology \& Geary Institute, University College Dublin

Chapter for Oxford Handbook of Poverty and Society

14 October 2012 


\section{MATERIAL DEPRIVATION AND CONSUMPTION}

\section{Introduction}

Research on poverty in rich counties has relied primarily on household income to capture living standards and distinguish those in poverty. This is also true of official poverty measurement and monitoring for policy purposes. However, as awareness has been increasing of the limitations of income as the sole means of capturing both levels of poverty and the underlying processes, there has been a fundamental shift towards a multidimensional approach. However, a variety of obstacles, relating to the conceptual and empirical underpinnings of existing research, lie in the path of such implementation (Grusky and Weeden, 2007; Kakwani and Silber, 2007, Thorbecke, 2007). In this chapter we provide an overview of the advantages of supplementing information relating to income with additional data relating to life-style deprivation and consumption

In a developing country context, manifest material deprivation and inadequate levels of consumption have always been central to the conceptualisation of poverty and living standards, and direct measures of failure to meet "basic needs" are commonly used alongside income-based measures such as the World Bank's “dollar a day" standard. In contrast, both research and official poverty monitoring in rich countries typically relies primarily on household income. Recently, though, an increasing awareness of the limitations of income has been reflected in a focus on the role which non-monetary measures of deprivation can play in capturing and understanding poverty and exclusion. This is illustrated most strikingly by the fact that the poverty reduction target for 2020 adopted by the European Commission in 2010 includes as one component a direct measure of material deprivation. (Nolan and 
Whelan, 2011, European Commission, 2011) This is part of a broader interest, at both research and policy levels, in developing multidimensional approaches to measuring and monitoring poverty and exclusion, on the understanding that no single indicator can be expected to adequately capture such complex concepts.

In this chapter we first provide an overview of recent research on material deprivation, seen primarily as a means to go 'beyond income' in capturing poverty and exclusion. We then focus on measuring deprivation, with some illustrations using comparative data for the countries of the EU, the broadest set of rich(er) countries for which comparative data are available. The mismatch between low income and measured deprivation is discussed, incorporating both longitudinal and cross-sectional perspectives.

In responding to the issues raised by the somewhat different pictures provided by income and deprivation, we first subject the notion of multidimensionality to critical scrutiny. Our starting point is that the case for a multidimensional approach has to be argued and demonstrated rather than assumed. We then proceed to focus on the measurement issues raised in the implementation of multidimensional approaches. In particular, we will seek to establish what can be learned from recent attempts to develop measures than can be decomposed by dimension. The issues involved will once again be addressed with illustrative applications using comparative material deprivation data for European countries. We will proceed to deal with a range of literature that focuses on conceptual and empirical issues relating to the contrast between income and consumption. Finally some key conclusions in relation to poverty, material deprivation and consumption will be highlighted. 


\section{Going Beyond Income in Capturing Poverty}

Most research on poverty takes as a point of departure the definition that people are in poverty when "their resources are so seriously below those commanded by the average individual or family that they are, in effect, excluded from ordinary living patterns, customs and activities" (Townsend, 1979). Poverty from this starting-point has two core elements: it is about inability to participate, which is attributable to inadequate resources. While most quantitative research employs income to distinguish the poor, this reliance on income has been increasingly questioned, and in that context the potential uses of direct measures of deprivation have come to the fore. While the use of non-monetary indicators in monitoring living conditions or quality of life has a long history, their use in capturing deprivation and poverty received a major impetus with Townsend's pioneering British study (1979). As these indicators became more widely available, they underpinned a more radical critique: that reliance on income actually fails to identify those who are unable to participate in their societies due to lack of resources (Ringen, 1988). Since then an extensive research literature on measures of material deprivation in OECD countries has grown up, the review by Boarini and Mira d'Ercole (2006) listing over a hundred studies covering a wide range of countries. In Europe the widespread adoption of the terminology of social exclusion/inclusion reflected inter alia a concern that focusing simply on income misses an important part of the picture, and reinforced the interest in material deprivation, and more broadly in multi-dimensional approaches to measuring poverty and exclusion (Nolan and Whelan, 2007, Burchardt, Le Grand. and Piachaud, 2002; Boarini and Mira D'Ercole, 2006; Bradshaw and Finch, 2003). There has also been significant interest in measuring and investigating material deprivation in OECD countries outside Europe, as in Headey (2008) Saunders et al (2007) and Scutella et al (2009) for Australia, and Jensen et al (2002) and Perry (2011) for New Zealand. The use of 
deprivation indicators in a US context has been more limited until recently (though see Mayer and Jencks, 1989, Mayer, 1993, Baumann, 1998, 1999, 2003), leading Blank to conclude that

"We should catch up with our European cousins and, like them; work to develop multiple measures of economic deprivation" (2008: 252)

A much more limited set of cross-country studies employs non-monetary indicators to capture and analyse poverty and exclusion in a comparative perspective. Studies covering a few countries using national data sources include Halleröd et al's (2006) analysis of Britain, Finland and Sweden, Saunders and Adelman (2006) on Australia and Britain, and Mayer's (1993) comparison of the USA with Canada, Sweden and Germany. Drawing on a variety of sources and studies with somewhat different definitions and measurement procedures, Boarini and Mira d'Ercole (2006) present a range of comparative data for OECD countries on the percentage of households unable to satisfy "basic needs" and basic leisure activities, lacking various consumer durables, in poor housing conditions etc. There are also now a significant number of comparative studies for the EU, starting with the pre-enlargement countries covered by the European Community Household Panel survey,). More recently, studies making use of data emerging from the EU-Statistics on Income and Living Conditions data-generation process from the mid-2000s. ${ }^{1}$ The study by Fusco, Guio and Marlier (2010) were carried out in association with Eurostat with a particular eye to the use of deprivation indicators in the EU's social inclusion process, with such a material deprivation indicator being adopted at EU level in 2010, based on a set of nine deprivation items.

\footnotetext{
${ }^{1}$ See Nolan \& Whelan (2011) for a detailed set of references.
} 


\section{Measuring Deprivation}

The material deprivation indicator adopted by the EU is based on data from the ambitious Statistics on Income and Living Conditions (EU-SILC) data-gathering process; these exceptionally rich comparative data on deprivation from this source will be used here to illustrate some core issues and approaches in measuring deprivation, in particular the special module on deprivation included with the 2009 wave of EU-SILC. We seek to focus as far as possible on enforced deprivation. Where the question format allows therefore we count an individual/household only where they indicate they that are lacking an item because they cannot afford it. In other cases where this information is not available but where it is implausible that absence occurs on a voluntary basis absence per se is taken as sufficient to constitute deprivation. Response rates tend to be extremely high for such items and the key measurement issues tend to relate to reliability, particularly cross-national reliability.

The recent SU-SILC data allows four distinct dimensions of deprivation to be identified via factor analysis, the most commonly-adopted approach, which providing a solid basis (in terms of measured reliability) for comparative European analysis (see Nolan and Whelan, 2011, Whelan and Maître, forthcoming):

- Basic Deprivation which comprises items relating to enforced absence of a meal, clothes, a leisure activity, a holiday, a meal with meat or a vegetarian alternative, adequate home heating, shoes.

- Consumption Deprivation comprises three items relating to a PC, a car and an internet connection. It is obviously a rather limited measure and it would be preferable to have a number of additional items.

- Health. This is captured by three items relating to the health of the HRP. These include current self-defined health status, restrictions on current activity and the presence of a chronic illness.

- Neighbourhood Environment. This captures the quality of the neighbourhood/area environment with a set of five items that include litter, damaged public amenities, pollution. ${ }^{2}$

\footnotetext{
${ }^{2}$ For an alternative analysis of the dimensionality of deprivation employing the EU-SILC 2009 special deprivation module and a comprehensive discussion of the data base see Guio, Gordon and Marlier (2012).
} 
Table 1 shows the levels of deprivation on these dimensions across twenty European countries, together with conventional relative income poverty rates using the $60 \%$ of median threshold (which are termed 'at-risk-of-poverty rates' in the EU's social indicators, or ARP for short here). For ease of interpretation we have ordered countries by gross national disposable income per capita $(\mathrm{GNDH}){ }^{3}$ The measures were constructed using prevalence weighting across the countries included, weighting each item by the proportion of households as a whole possessing an item or not experiencing the type of deprivation in question. Scores were normalised on each of these dimensions so that they have a potential range running from 0 - indicating that the household is deprived in relation to none of the items included in the index - to 1 , indicating that they experience deprivation in relation to all of the items.

In Table 1, where counties are by gross national disposable income per head (GNDH) we observe rather modest variation across countries in relative income poverty rates. There is no clear relationship between the ARP measure and GNDH as captured by income per capita. In contrast, the basic deprivation dimension shows much greater variation and also varies systematically by income level. The intra class correlation coefficient (ICC) captures the proportion of the total variance accounted for by between country differences, and can also be interpreted as the expected correlation between two randomly drawn households within a particular country (Hox, 2010:14-15). In the case of basic deprivation the ICC value of 0.244 indicates that between countries variation accounts for $24.4 \%$ of the variance in economic stress while within country variation captures $75.6 \%$. The consumption deprivation measure is also associated with income level but variation across country is more modest, with an ICC value of 0.112 . The remaining dimensions exhibit very weak correlations with income per capita in the country, with ICC values of 0.046 and 0.018 respectively for neighbourhood deprivation and health. Correlations between the deprivation dimensions are modest: there

\footnotetext{
${ }^{3}$ Sweden has been excluded from the analysis due to serious missing data problems in relation to the deprivation items.
} 
are interrelated risks rather than strongly overlapping patterns of deprivation. Not only does the importance of cross-nation variation differ across these dimensions, it is clear that socioeconomic patterning in relation these relatively distinct outcomes must also differ significantly. The basic deprivation measure is by far the most reliable measure available for comparative European analysis of deprivation, and displays the highest average correlation with the other dimensions of deprivation. It comes closest to capturing a form of generalized deprivation in which those deprived on that dimension are also significantly more likely to be deprived on a range of other dimensions. If one's interest is in capturing exclusion from customary pattern of living due to lack of resources, what is required is a measure of deprivation that is significantly related to but by no means identical to income. Further analysis shows that basic deprivation is the dimension most closely correlated with disposable household income and national disposable income per capita. It is also the deprivation outcome most closely associated with subjective economic stress, for which measures are also available in EU-SILC. However, reflecting the mediating role of national reference groups, the impact of an absolute increase in basic deprivation is actually stronger in high income and low inequality countries (Delhey and Kohler, 2006; Fahey, 2007; Whelan and Maître, 2009, 2012a). 
Table 1: Deprivation Dimensions and Relative Income Poverty(ARP) by Country, EU-SILC 2009

\begin{tabular}{|c|c|c|c|c|c|}
\hline & Basic & Consumption & Health & Neighbourhood & ARP \\
\hline & Mean & Mean & Mean & Mean & $\%$ \\
\hline Luxembourg & 0.052 & 0.011 & 0.164 & 0.124 & 14.9 \\
\hline Norway & 0.031 & 0.023 & 0.170 & 0.065 & 11.7 \\
\hline Netherlands & 0.052 & 0.022 & 0.176 & 0.176 & 11.1 \\
\hline Austria & 0.093 & 0.049 & 0.242 & 0.137 & 12.0 \\
\hline Denmark & 0.044 & 0.039 & 0.141 & 0.141 & 13.2 \\
\hline Germany & 0.128 & 0.054 & 0.195 & 0.105 & 15.5 \\
\hline Belgium & 0.098 & 0.058 & 0.184 & 0.147 & 14.6 \\
\hline Finland & 0.044 & 0.049 & 0.085 & 0.085 & 13.8 \\
\hline United Kingdom & 0.099 & 0.042 & 0.196 & 0.214 & 17.3 \\
\hline France & 0.118 & 0.048 & 0.217 & 0.217 & 12.9 \\
\hline Spain & 0.111 & 0.075 & 0.213 & 0.135 & 19.5 \\
\hline Ireland & 0.095 & 0.077 & 0.152 & 0.144 & 15.0 \\
\hline Italy & 0.114 & 0.041 & 0.192 & 0.177 & 18.4 \\
\hline Iceland & 0.040 & 0.001 & 0.134 & 0.081 & 15.0 \\
\hline Cyprus & 0.129 & 0.040 & 0.192 & 0.153 & 16.2 \\
\hline Greece & 0.161 & 0.113 & 0.170 & 0.201 & 19.7 \\
\hline Slovenia & 0.132 & 0.042 & 0.203 & 0.154 & 11.3 \\
\hline Portugal & 0.249 & 0.114 & 0.278 & 0.164 & 17.9 \\
\hline Czech Republic & 0.126 & 0.083 & 0.211 & 0.174 & 8.6 \\
\hline Malta & 0.198 & 0.026 & 0.166 & 0.216 & 15.1 \\
\hline Slovakia & 0.171 & 0.138 & 0.280 & 0.251 & 11.0 \\
\hline Estonia & 0.137 & 0.103 & 0.237 & 0.128 & 19.7 \\
\hline Hungary & 0.314 & 0.164 & 0.290 & 0.200 & 12.4 \\
\hline Poland & 0.205 & 0.137 & 0.248 & 0.134 & 17.1 \\
\hline Lithuania & 0.253 & 0.127 & 0.203 & 0.137 & 20.6 \\
\hline Latvia & 0.297 & 0.172 & 0.252 & 0.221 & 25.7 \\
\hline Romania & 0.413 & 0.351 & 0.198 & 0.198 & 22.4 \\
\hline Bulgaria & 0.465 & 0.256 & 0.153 & 0.229 & 21.8 \\
\hline $\begin{array}{l}\text { Intra Class } \\
\text { Correlation (ICC) }\end{array}$ & 0.244 & 0,117 & 0.015 & 0.043 & \\
\hline
\end{tabular}

Earlier studies such as Kenworthy, Epstein and Duerr (2011) have suggested a weak relationship between deprivation and GDP at country level. However, multilevel analysis by Whelan and Maître (forthcoming) shows basic deprivation to be systematically related to both gross national disposable income per capita and to lesser degree income inequality (as reflected in the Gini coefficient), as well as a range of socio-economic factors. Patterns of social stratification by class, education, unemployment, marital disruption and number of children are significantly sharper in less prosperous countries with lower levels of national income per head. Correspondingly, cross-national differences in basic deprivation are 
significantly greater among disadvantaged groups than among their more favoured counterparts.

\section{Poverty and the Mismatch between Income and Deprivation}

Going back to Ringen (1988), the mismatch between low income and measured deprivation at a point in time has been highlighted as a concern with respect to reliance on income-based poverty measures. The highest correlation with income relates to basic deprivation. In Table 2 we breakdown the correlation between equivalent disposable income for individuals and basic deprivation by country. The average population weighted correlation is -0.358 while the median correlation is -0.307 . The range of correlations goes from a low of -0.141 in Iceland to a high of -0.521 in Bulgaria. There is a clear tendency for correlations to be higher in the less affluent counties. The lowest correlations are observed for the affluent countries normally allocated to the social democratic welfare regime. For Denmark, Finland, Iceland, the Netherlands and Norway the average correlation is- 0.177 . In contrast for the six least affluent counties the correlation is -0.396 . The correlation is clearly significant but very far from perfect. The level of the association appears to be influenced national income levels and, to some extent to by welfare regime. The findings suggest that the relationship is influenced by the extent to which current disposable income serves as an adequate proxy for longer term command over resources and the extent to which needs are satisfied predominantly through market mechanisms relative to welfare state intervention. 


\begin{tabular}{|l|c|}
\hline \multicolumn{2}{|l|}{ Table 2: Correlation between Equivalent Disposable Income and Basic Deprivation } \\
\hline Luxembourg & Correlation \\
\hline Norway & -0.249 \\
\hline Netherlands & -0.180 \\
\hline Austria & -0.209 \\
\hline Denmark & -0.330 \\
\hline Germany & -0.149 \\
\hline Belgium & -0.149 \\
\hline Finland & -0.274 \\
\hline United Kingdom & -0.204 \\
\hline France & -0.260 \\
\hline Spain & -0.262 \\
\hline Ireland & -0.345 \\
\hline Italy & -0.309 \\
\hline Iceland & -0.305 \\
\hline Cyprus & -0.141 \\
\hline Greece & -0.287 \\
\hline Slovenia & -0.440 \\
\hline Portugal & -0.349 \\
\hline Czech Republic & -0.374 \\
\hline Malta & -0.297 \\
\hline Slovakia & -0.294 \\
\hline Estonia & -0364 \\
\hline Hungary & -0.377 \\
\hline Poland & -0.417 \\
\hline Lithuania & -0.328 \\
\hline Latvia & -0.328 \\
\hline Romania & -0.349 \\
\hline Bulgaria & -0.400 \\
\hline Population weighted average & -0.521 \\
\hline Median Correlation & -0.358 \\
\hline & 0.307 \\
\hline
\end{tabular}

For many, the solution to the income-deprivation mismatch has been seen to lie in using longitudinal measures of income, on the basis that low income at a point in time may not be an accurate reflection of 'permanent' income or living standards. On this basis, it may be argued that by paying appropriate attention to the longitudinal aspects of income poverty, or income and wealth, one can avoid the need for non-monetary indicators and multidimensional approaches. Panel research has shown that movements into and out of poverty are a great deal more frequent than had been supposed, and that a far greater proportion of the population experience poverty at some point than suggested by crosssectional studies. ${ }^{4}$ By extending the measure of income poverty over time, the expectation

\footnotetext{
${ }^{4}$ See Breen and Moisio (2004) Jarvis and Jenkins (1997).
} 
would be that such a measure would be more strongly related to deprivation, reducing the income poverty-deprivation mismatch.

Implicit in this approach is the assumption that deprivation measures are more stable than income over time, with the consequence that current level of deprivation is a significantly better indicator of persistent deprivation than current income is of its longitudinal counterpart. Given this, the mismatch problem, evident at the cross-sectional level, would be largely resolved by taking poverty experience over time into account. However, contrary to expectations, the level of mismatch at the longitudinal level is no less than for point-in-time measures (Whelan, Layte and Maître, 2004). Further investigation by Whelan and Maître (2006) estimated models of dynamics incorporating structural and error components, which were found to perform equally well in accounting for poverty and deprivation dynamics. Short-term changes over time in deprivation (at the individual/household level) are very weakly related to corresponding variations in income, with measurement error in each contributing, while in contrast mean deprivation over a period is highly correlated with income averaged over a period (Berthoud et al 2004, Berthoud and Bryan, 2010). However, there is no evidence that differences in the determinants of poverty and deprivation persistence found in cross-sectional analysis are a consequence of there being more error in the measurement of income than deprivation. Although income poverty and deprivation are substantially correlated, even when measured over reasonable periods of time and allowing for measurement error they continue to tap relatively distinct phenomenon (Breen and Mosio, 2004, Whelan and Maître, 2006.

We should stress that we are not proposing a sole reliance on deprivation measures. Income continues to be a crucial indicator and deprivation measures are of a limited value unless we 
can develop an understanding of the manner in which they are related to longer term accumulation and erosion of resources over time. It is perhaps worth keeping in mind that, viewed from a broader sociological perspective on social stratification, the fact that the complexities of such process are far from being adequately captured by a single indicator relating to current disposable income is far from surprising. Nolan and Whelan (2011: 108119) review a range of evidence demonstrating that social class differentiation is significantly sharper where we focus on joint exposure to income poverty and deprivation and where we employ longitudinal rather than cross-sectional measures. ${ }^{5}$ Ultimately, as Goldthorpe (2010) argues, issues such as this must be addressed within a broader framework relating to the socially structured nature of disadvantage and social inequality.

While continuing efforts to develop a more adequate understanding of the dynamics of the relating between income and deprivation are a priority, if poverty continues to be defined in terms of "exclusion from a minimally acceptable standard of living through a lack of resources", the longitudinal measures of income poverty currently available to us cannot be taken on their own as providing valid measures of the underlying construct: direct measures of material deprivation continue to be a valuable complement. If one wants to use both indicators of deprivation or consumption and low income to capture levels of and trends in poverty and identify those most at risk, what is the best way of doing so? More broadly, if one wants to incorporate various dimensions of poverty or exclusion rather than be confined to one (notably income), how is this best approached?

\footnotetext{
${ }^{5}$ For empirical support for these claims see Whelan, Watson \& Maître (2010).
} 


\section{Multidimensional Poverty}

A particularly ambitious statement of what a multidimensional approach to poverty measurement should encapsulate is provided below.

"Poverty is not just the absence of income or even the material deprivation that accompanies it. It is both of these and everything that follows from them: the hassle; the hard work; the stress; the budgeting; the conflict the shame; the degraded environment; the isolation; the helplessness; the ill-health; the misfortune - and much else that, taken together, is both a reasoned and involuntary responses to hardship and which may, quite often, serve to exacerbate it" (Tomlinson and Walker, 2009: 20).

By these standards pretty well all measures of poverty constructed at the national level will fail the 'multidimensionality' test. Providing such a multidimensional account of poverty could be realistically achieved only by a mixed approach combining both quantitative and qualitative techniques. A particularly good example of the value of such a multi- pronged approach is provided by childhood poverty and deprivation. A recent strand of research explores the impact of poverty from the perspective of children themselves. In an in-depth study of 40 children (aged 10-17) from low income families Ridge (2002) found that effects of poverty and disadvantage can permeate every aspect of children's lives - material, social and emotional. Impacts that were specific to children included limited access to their own economic resources, access to transport and the importance of friendship. However, a clear distinction needs to be maintained between understanding the multifaceted nature of poverty, which clearly requires a mixed method approach and identifying those exposed to multidimensional deprivation (Nolan \& Whelan, 2007). It is clear that national quantitative based measures cannot deliver on the former objective. However, it does not follow that adult indicators cannot be successful in identifying children exposed to multidimensional 
deprivation. For example, Whelan and Maître (2012b) employing both adult and childhood national deprivation measures have shown that the former are largely successful in capturing those exposed to childhood deprivation.

A variety of analytic strategies have been employed in efforts to develop quantitative multidimensional approaches. These include latent class analysis (De Wilde, 2004; Moisio, 2004; Grusky and Weeden, 2007; Whelan and Maître 2005), structural equation modelling (Carle, Bauman and Short 2009; Tomlinson, Walker and Williams, 2008), item response theory (Capellari and Jenkins, 2007), and self-organising maps (Pisati et al 2009). In practical application, one rather straightforward approach has been to focus attention on those who are measured at both on low income and experiencing high levels of deprivation - what has been termed the 'consistently poor' (see Nolan and Whelan, 1996). By contrast, the poverty target adopted in 2010 by the European Union includes in the target population those who meet any one of three criteria - being below an income threshold, above a deprivation threshold, or in a 'workless' household. (For an in-depth examination of this target see Nolan and Whelan, 2011).

This illustrates the contrast between what Atkinson (2003) terms the union approach, which includes all those deprived in relation to any of a set of dimensions, and the intersection approach, which requires that an individual is deprived on each of the dimensions under consideration. While the former typically produces very high estimates of multidimensional poverty, the latter generally results in extremely low estimates. This distinction has received little explicit discussion in the social policy literature on poverty and social exclusion. However, the dilemma it presents is captured in Room's (1999: 171) discussion of notions of continuity and catastrophe in the social exclusion literature, and it is also recognised in Levitas et al's (2007) distinction between 'social exclusion' and 'deep exclusion'. The former 
refers to restriction of access to any of a wide range of commodities and services necessary for full participation in the society. 'Deep exclusion' on the other hand, focuses on deprivation across more than one dimension of disadvantage, resulting in severe negative consequences for quality of life, well-being and future life chances.

Recently, Alkire and Foster $(2007,2010,2011$ a \& b) have sought to develop alternatives to the union, intersection and uni-dimensional approaches, extending the Foster, Greer and Thorbecke (1984) class of indices widely employed with income poverty measures. Their approach has mostly been applied in the context of less developed counties (Alkire and Santos, 2010 and Alkie and Seth, 2011), but Whelan, Nolan and Maître (2012) have applied it to the EU, once again employing the data on deprivation from the 2009 special module in EU-SILC (2009). The focus is on five dimensions comprising ARP, basic deprivation, consumption deprivation, health and neighbourhood environment. Thresholds have been chosen for the remaining dimensions so as to produce numbers "poor" on each dimension as close as possible to the number below the national ARP threshold. The Alkire and Foster approach involves a dual cutoff approach. This involves choices by analysts employing the approach in relation to the appropriate threshold for each deprivation dimension included in the analysis and a decision on the number of dimensions on which an individual must be deprived to be classified as "poor".

Once an individual is identified as poor, the aggregation step builds upon the standard FGT methodology. Non poor individuals are excluded for further analysis information on the nonpoor does not affect the measure. Our focus in this here is on the adjusted head count ratio which is defined as $\mathrm{M}_{0=} \mu\left(\mathrm{g}^{\mathrm{O}}(\mathrm{k})\right.$ or the mean of the censored deprivation matrix. $\mathrm{M}_{0}$ has a potential range of values going from 0 to 1 . Where no one in the population experiences any 
of the deprivations in will take on a value of 0 and where all individuals experience deprivation on all items the value will be 1 . From column (i) of Table 3 , we can see that the observed range of values goes from 0.019 for Iceland to 0.291 in Romania. The intra class correlation coefficient (ICC) is 0.129 indicating the proportion of variance accounted for by between country differences. Values generally increase as country income levels decline. For the three lowest income countries the adjusted head count ratio (AHR) ranges between 0.25 and 0.31 . In other words, the multi-dimensionally poor experience an aggregate level of deprivation that reaches over 25 to $31 \%$ of that which would be observed if multidimensional poverty was universal and all poor individuals were deprived on all items. Clearly the $\mathrm{M}_{0}$ is a great deal more successful in capturing cross-country variation than the ARP indicator.

The figures for $\mathrm{M}_{0}$ can be contrasted with those for those for the union and intersection counts for the five dimensions involved in our analysis as set out in columns (ii) and (iii). For the former, where all individuals experiencing deprivation on any of the dimensions is counted the levels range from a lows of 0.381 in Luxembourg and 0.387 in Denmark to highs of 0.808 and 0.821 in Bulgaria and Romania respectively. The figures in relation to the intersection of the dimensions, involving deprivation on all five dimensions, provide a sharp contrast. Here the counts range from scores of effectively zero in most affluent countries to 0.012 in Bulgaria and 0.016 in Latvia. The fact that the income variable is defined in relative terms contributes to the extreme nature of our results. However, they are generally consistent with earlier research focusing on multiple deprivation in the European Union (Tsakloglou and Papadopouous, 2002, Whelan. Layte and Maître, 2002, Whelan and Maître, 2005). The AHDR clearly provides a middle ground between the union approach where in excess of $40 \%$ of individuals on most EU countries are counted as deprived and the intersection approach where hardly any one is counted as multiply deprived even in the least affluent countries. 


\begin{tabular}{|c|c|c|c|}
\hline & $\begin{array}{c}\text { (i) } \\
\text { MD Adjusted Headcount } \\
\text { Ratio }\end{array}$ & $\begin{array}{c}\text { (ii) } \\
\text { Union }\end{array}$ & $\begin{array}{c}\text { (iii) } \\
\text { Intersection }\end{array}$ \\
\hline Luxembourg & .054 & .381 & .001 \\
\hline Norway & .060 & .434 & .001 \\
\hline Netherlands & .060 & .434 & .001 \\
\hline Austria & .083 & .465 & .004 \\
\hline Denmark & .054 & .387 & .002 \\
\hline Germany & .107 & .489 & .006 \\
\hline Belgium & .091 & .423 & .007 \\
\hline Finland & .066 & .409 & .002 \\
\hline UK & .105 & .544 & .002 \\
\hline France & .081 & .438 & .001 \\
\hline Spain & .102 & .531 & .002 \\
\hline Ireland & .096 & .455 & .002 \\
\hline Italy & .092 & .512 & .002 \\
\hline Iceland & .030 & .310 & .000 \\
\hline Cyprus & .078 & .438 & .001 \\
\hline Greece & .136 & .606 & .004 \\
\hline Slovenia & .082 & .446 & .004 \\
\hline Portugal & .171 & .617 & .005 \\
\hline Czech Republic & .102 & .569 & .003 \\
\hline Malta & .088 & .522 & .001 \\
\hline Slovakia & .158 & .668 & .005 \\
\hline Estonia & .123 & .551 & .002 \\
\hline Hungary & .240 & .770 & .006 \\
\hline Poland &. .157 & .637 & .005 \\
\hline Lithuania & .170 & .611 & .008 \\
\hline Latvia & .253 & .731 & .016 \\
\hline Romania & ,313 & .821 & .006 \\
\hline Bulgaria & .289 & .808 & 0.012 \\
\hline
\end{tabular}




\section{Decomposition of Multidimensional Poverty by Dimension}

One of the advantages of the $\mathrm{M}_{0}$ measures is that is that it is decomposable in terms of deprivation dimensions. In Table 4 we show this decomposition broken down by country. It is clear that there is substantial variation across countries in the relative importance of dimensions. In the more affluent countries basic and consumption deprivation play a modest role with the dimensions making the greatest contribution being the ARP indicator and health deprivation. The neighborhood dimension has its highest values in relatively affluent countries such as the Netherlands and the UK. Multidimensional poverty is influenced by both deprivation levels and the association between dimensions. Individuals are counted as poor only where they are deprived on two or more dimensions. High levels of deprivation on individual dimensions together with low levels of association produce low levels of poverty. For the more affluent countries the distribution of levels of deprivation and the degree of association between income poverty and health are sufficient to lead to these factors dominating while others play a much less significant role.

For countries in the middle range of affluence, individual dimensions contribute more evenly. However, the role of the consumption dimension remains modest in a number of cases and the role of neighborhood environment remains variable. In France and Spain the ARP measure, basic deprivation and health contribute relatively evenly while the impact of consumption and neighborhood environment are weaker. In Italy all dimensions, other than consumption, make a proportionate contribution. For Greece and Ireland we observe a relatively uniform distribution across dimensions. For the Czech Republic and Slovakia the contribution of ARP is weaker than in most counties while the impact of health is stronger than for the other dimensions. For most of the remaining less affluent counties, basic deprivation in particular but also consumption deprivation come to play an important role. 
For Romania and Bulgaria the basic deprivation rates are .329 and .347 and the combined basic and consumption deprivation rates are .638 and .587 . In the latter case the comparable figures for the Netherlands and Denmark are .240 and .337.

\begin{tabular}{|c|c|c|c|c|c|c|}
\hline & ARP & Basic & Consumption & Health & Neighbourhood & Total \\
\hline & $\%$ & $\%$ & $\%$ & $\%$ & $\%$ & $\%$ \\
\hline Luxembourg & .276 & .173 & .146 & .227 & .178 & 1.0 \\
\hline Norway & .281 & .128 & .220 & .258 & .112 & 1.0 \\
\hline Netherlands & .199 & .107 & .133 & .242 & ,246 & 1.0 \\
\hline Austria & .190 & .205 & .180 & .265 & .160 & 1.0 \\
\hline Denmark & .236 & .111 & .226 & .254 & .172 & 1.0 \\
\hline Germany & .215 & .228 & .193 & .228 & .136 & 1.0 \\
\hline Belgium & .224 & .186 & .181 & .228 & .177 & 1,0 \\
\hline Finland & .265 & .092 & .243 & .269 & .132 & 1.0 \\
\hline United Kingdom & .212 & .174 & .136 & .234 & .240 & 1.0 \\
\hline France & .206 & .233 & .179 & .228 & .154 & 1.0 \\
\hline Spain & .238 & .154 & .216 & .237 & .156 & 1.0 \\
\hline Ireland & .203 & .154 & .243 & .217 & .182 & 1.0 \\
\hline $\begin{array}{l}\text { Italy } \\
\end{array}$ & .238 & .208 & .116 & .230 & .208 & 1.0 \\
\hline Iceland & .243 & .143 & .125 & .325 & .166 & 1.0 \\
\hline Cyprus & .257 & .197 & .153 & .278 & .116 & 1.0 \\
\hline Greece & .223 & .208 & .214 & .176 & .179 & 1.0 \\
\hline Slovenia & .173 & .247 & .156 & .262 & .162 & 1.0 \\
\hline Portugal &. .161 & .286 & .211 & .226 & .116 & 1.0 \\
\hline Czech Republic & .130 & .164 & .201 & .282 & .215 & 1.0 \\
\hline Malta & .210 & .286 & .119 & .183 & .202 & 1.0 \\
\hline Slovakia & .108 & .184 & .238 & .243 & .226 & 1.0 \\
\hline Estonia & .230 & .153 & .250 & .246 & .126 & 1.0 \\
\hline Hungary & .094 & .289 & .220 & .205 & .192 & 1.0 \\
\hline Poland & .170 & .242 & .241 & .226 & .120 & 1.0 \\
\hline Lithuania & .201 & .321 & .234 & .220 & .119 & 1.0 \\
\hline Latvia & .179 & .256 & .225 & .187 & .154 & 1.0 \\
\hline Romania & .134 & .329 & .309 & .123 & .106 & 1.0 \\
\hline Bulgaria & .144 & .347 & .240 & .120 & .150 & $1 . .0$ \\
\hline
\end{tabular}

Multidimensional poverty, defined in the foregoing manner, varies systematically across socio-demographic groups. The impact of key factors such as social class and age group varies significantly across counties with the former playing a more significant role in less affluent countries and the latter having its most substantial influence in their more affluent counterparts. National income levels are important in accounting for cross-national variation both in themselves and in the manner in which they interact with key socio-economic 
variables. In contrast, income inequality and welfare regime effects have no additional impact once we control for the foregoing factors (Whelan et al 2012).

In relation to outcomes such as subjective economic stress there is a significant loss of explanatory power in subsuming different deprivation profiles under the multidimensional poverty label rather than focusing on a variable such as basic deprivation chosen on the grounds of particular theoretical consideration (Whelan and Maítre, 2012). Similarly, the variable impact of socio-economic factors across counties with different aggregate income levels derives, in part, from corresponding difference in the dominant multidimensional profiles. One is not exactly comparing like with like. However, focusing on current outcomes rather than also including drivers to some extent to guard against the dangers to which Ravallion (2011) directs attention, that recognising that poverty is multidimensional does not necessarily imply the use of a multidimensional poverty index rather than a focus on a range of multiple indicators as in the case of the Millennium Development Goals. The possibility exists and that the former approach may lead to confusion rather than clarity

Obviously the extent to which aggregation may create difficulties is related to the choice of dimensions included in the analysis and the extent to which it is reasonable to assign weights, whether equal or unequal. This is something which must be determined on the basis of substantive rather than technical considerations. The breadth of the of dimensions employed in applying this method to developing countries (Alkire and Santos, 2010 \& Alkire \& Seth, 2011) present substantially greater difficulties in this respect than the deprivation analysis relating to European countries that we have discussed in this chapter. We have also made clear that the choice of dimensions to include in the analysis and the thresholds for the dimensions included and the weights to apply lie with the analyst rather than deriving from the method. Any such findings can be subjected to sensitivity analysis in order to assess the robustness of the findings. If a multidimensional index of this kind is to be utilised it is 
clearly preferable that is constructed so that it characterised by a range of desirable axiomatic properties rather than on an ad hoc basis. However, the construction of such an index is not an alternative to the development of improved indices for individual dimensions. Nor is this the only approach to tapping such dimensionality: for example, latent class approaches focusing on distinctive risk profiles rather patterning of current outcomes offer a different but complementary perspective (Grusky and Weeden, 2007, Whelan and Maître, 2010b).

\section{Consumption and Poverty}

Consumption has become a subject of heightened interest recently in the literatures on poverty and inequality (Ringen 1988; Cutler and Katz, 1991; Slesnick 1991, 1994, 2001; Mayer and Jencks, 1993; Johnson, 2004; Johnson, Smeeding and Torrey, 2005; Krueger and Perri, 2006; Brewer, Goodman, Leicester 2006; Meyer and Sullivan, 2003, 2004, 2007, 2010, 2011, 2012). Building on the existing criticism of the accuracy of income as an indicator of people's real conditions and material well-being, various scholars have argued that consumption must be taken into consideration when determining the poverty status.

The focus on consumption as a measure of well-being has been particularly prominent in economics, in part due to several influential analyses by Nobel laureate economists Milton Friedman and Franco Modigliani, in the 1950s and 1960s, which argued that consumption expenditures constitute a more accurate indicator of economic well-being since they are more stable than current incomes across time. According to Friedman's (1957) “permanent income hypothesis," temporary changes in income do not really affect consumption decisions since individuals base their consumption choices on a long-term view of their income. Similarly, Modigliani's "life-cycle thesis" argues that "consumption and saving decisions of households at each point of time reflect a more or less conscious attempt at achieving the preferred 
distribution of consumption over the life cycle, subject to the constraint imposed by the resources accruing to the household over its lifetime" (1966: 162). In other words, both theories hold that individuals and households tailor their consumption patterns to their needs rather independently of their incomes ${ }^{6}$.

More recently, American economist Slesnick (1991, 1994, 2001) argued quite forcefully in favour of shifting the focus of poverty and inequality studies to consumption. Meyer and Sullivan (2003, 2007), argued, likewise, that consumption provides a more appropriate measure of well-being than income for those with few resources.

In sociology on the other hand, a consumption-based view of poverty and well-being has never really taken hold. Sociological interest in consumption has largely remained limited to qualitative studies examining its relationship to status (e.g. Veblen 1899; Bourdieu 1984). Although Ringen (1988: 263) argued that income provides an "indirect" measure of poverty and consumption a "direct" one, and that "one only needs to introduce some very simple and tentative information in the standard of consumption to demonstrate the inadequacy of relying on income information alone in the measurement of poverty", the poverty and consumption link has remained rather neglected, and there have been very few quantitative and comparative studies on the subject to date. This is rather surprising for even a cursory look at income and consumption statistics in selected European nations shows quite clearly that our poverty estimates are likely to change significantly when consumption is brought into the picture. Data from Eurostat on income and consumption included in the Table 5 gives a good preliminary sense about the discrepancy between income and consumption measures in selected European nations. The mean consumption expenditure of households in

\footnotetext{
${ }^{6}$ See Deaton (2005) for an extensive discussion on Modigliani’s "life-cycle thesis".
} 
the first income quintile (in PPS) seems to be significantly lower than the top cut-off income level (in PPS) for households in the first quintile.

Table 5. Consumption expenditure per household in the first income quintile (mean value in PPS) versus top cut-off income level, first quintile (in PPS)

\begin{tabular}{|l|c|c|c|c|c|c|}
\hline & \multicolumn{3}{|c|}{ Income } & \multicolumn{3}{c|}{ Consumption } \\
\hline Belgium & $\mathbf{1 9 9 5}$ & $\mathbf{1 9 9 9}$ & $\mathbf{2 0 0 5}$ & $\mathbf{1 9 9 4}$ & $\mathbf{1 9 9 9}$ & $\mathbf{2 0 0 5}$ \\
\hline Germany & 8,211 & 9,842 & 10,164 & 18,933 & 18,699 & 18,929 \\
\hline Ireland & 8,169 & 10,141 & 11,039 & 11,132 & 12,490 & 14,388 \\
\hline Greece & 5,452 & 6,964 & 9,102 & 13,083 & 27,102 & 18,272 \\
\hline Spain & 3,843 & 4,677 & 6,515 & 10,285 & 12,570 & 18,617 \\
\hline France & 4,522 & 5,478 & 7,037 & 12,690 & 13,955 & 16,874 \\
\hline Italy & 7,537 & 8,685 & 9,852 & 13,843 & 15,457 & 18,069 \\
\hline Luxembourg & 5,335 & 6,655 & 8,394 & 11,321 & 19,290 & $:$ \\
\hline Netherlands & 12,943 & 14,319 & 19,103 & 26,190 & 26,921 & 21,139 \\
\hline Austria & 8,766 & 9,740 & 11,368 & 12,449 & 17,522 & 22,694 \\
\hline Portugal & 3,411 & 4,335 & 5,001 & 6,049 & 8,195 & 8,375 \\
\hline Finland & $:$ & 8,166 & 9,794 & 9,247 & 10,021 & 13,085 \\
\hline UK & 6,885 & 7,793 & 10,338 & 11,906 & 14,347 & 18,941 \\
\hline
\end{tabular}

\section{The Pros and Cons of Consumption Based Measures}

Several theoretical and empirical reasons have been advanced for taking into account what families actually consume in determining their poverty status. First, at a broad, theoretical level, it is argued that families and individuals "derive material well-being from the actual consumption of goods and services rather than from the receipt of income per se" (Johnson 2004: 2). As noted before, even when their income drops, families and individuals may still be able to sustain their levels of consumption by relying on their savings, or by taking advantage of various public and private mechanisms. Official poverty measures relying on income statistics, however, ignore various public and private mechanisms such as access to credit, increasing availability of affordable consumption products, or social transfers that affect what people are able to consume. Second, consumption can be divided into meaningful 
categories, such as food and housing, which makes it easier to get a sense of the actual nature of deprivation (Meyer and Sullivan, 2010). And third, research has shown that consumptionbased measures of well-being differ substantially from those based on income.

At the same time, using consumption as an indicator of poverty and other aspects of wellbeing raises a set of challenges and problems. Conceptually, consumption may not fully reflect a family's true well-being but simply mask the long-term challenges of increasing indebtedness given that it has remained largely credit-reliant over the past few decades in both advanced and developing nations. There are also major difficulties concerned with defining 'consumption' in operational terms, collecting the data necessary to construct an appropriate measure, and setting appropriate parameters for measurement (equivalence scale, measurement unit, and cost of living adjustment).

First, consumption measures are often based on family expenditure data. The difficulty of obtaining complete, accurate and comparable data on family expenditure renders adoption of a consumption-based index problematic (Smeeding 2009). Expenditure surveys are seen as among the most "difficult and expensive surveys" (Deaton and Grosh 2000) ${ }^{7}$. Moreover, as Smeeding (2009) notes, many countries collect consumption data solely for the purpose of providing weights for measuring the consumer price index, rather than capturing an accurate picture of consumption trends and habits. Largely due to these reasons, consumer expenditure surveys often rely on small sample sizes. Various sampling and non-sampling errors (e.g. differences in respondents' interpretation of questions, inability or unwillingness of the respondents to provide the required information, handling of missing data, etc.) may also

${ }^{7}$ Deaton and Grosh (2000) note that in the US, the Consumer Expenditure Survey (CEX) costs about five times as much per household as the current population survey (CPS), which is the main source for data on income, earnings, and employment. 
occur. As a result of these combined factors, the collected data might not provide an accurate representation of the consumption levels and habits of the population.

Second, consumption measures always involve some degree of imputation (Cutler and Katz 1991; Deaton and Grosh 2000; Slesnick 2001). Deaton and Grosh (2000) warn that such imputations need to be done with great care to avoid erroneous interpretations of the results in cases where such imputations have an important effect on the total consumption measure. The question of choice versus need remains unresolved in consumption-based measures of poverty (Smeeding 2009). The treatment of medical expenses deserves careful attention, for instance. As pointed out by Meyer (2007) and Meyer and Sullivan (2011), high medical expenses may be taken to reflect a higher standard of living, which would be erroneous. Similarly, how to reflect the consumption flow derived from home ownership is also debated among researchers.

Third, choice of the equivalence scale might also dramatically affect the results on the relative standard of living of different families. A lower equivalence scale implies that the family's resources will be adjusted upward, and vice-versa. Similarly, the choice of the unit of measurement affects the poverty rate and its composition (see Jencks et al 2004). Finally, as Jencks, et al. (2004) demonstrated, different price indexes (or cost-of-living adjustments) lead to a variety of changes in well-being and poverty.

All of the choices researchers have to make in addressing these various challenges concerned with collecting and constructing a consumption measure will inevitably affect poverty measures, and there is no consensus on how to resolve these issues (see Cutler and Katz 1992; Deaton and Grosh 2000; Jonhson 2012; Slesnick 1991, 1994, 2001). Differences in 
specific measures and parameters used lead researchers to different conclusions regarding poverty trends. For instance, speaking about poverty trends in the United States, Slesnick (1991, 1994, 200) argues that consumption data show that from 1980 through 1995 poverty fell considerably more than the corresponding income poverty rates. Similarly, examining shifts in the rate of poverty for those 65 and over between 1972 and 2004 within the employing varying measures based on income and consumption, Meyer and Sullivan (2007) argue that consumption based measures of poverty suggested greater improvements in wellbeing than are evident in alternative income based measures. Other scholars dispute these findings. Similarly, focusing on inequality trends in the United States, Krueger and Perri (2005) note that while both measures of inequality indicate an increase in inequality over the 1980s; consumption inequality increased at a slower rate, and remained flat while income inequality continued to rise throughout the 1990s. Cutler and Katz (1992), on the other hand, argue that consumption poverty in the United States rose more than income poverty during the 1970s, while the distributions of income and consumption have remained relatively flat since the early 1980 s.

As noted before, neither the methodological challenges that concern the use of consumptionbased measures nor the conflicting findings that result from them undermine the usefulness of consumption measures for the measurement of poverty. However, given that these findings might have substantial implications for social policies designed to deal with poverty and related issues, it is important to proceed with caution when interpreting data. The use of both consumption and income measures together may be the best course of action in order to fully examine the levels of and trends in poverty (Johnson 2004). 


\section{Conclusions}

The central message of this chapter is that research on poverty in rich counties is undergoing a fundamental shift away from reliance on household income to capture living standards and distinguish those in poverty, towards incorporation of a variety of non-monetary indicators within a multidimensional framework, feeding through to practice in official poverty measurement and monitoring for policy purposes. This reflects increasing recognition of both the limitations of relying solely on income in capturing poverty and studying the underlying processes that create it, and of the potential richness of multidimensional perspectives and approaches incorporating non-monetary indicators. This shift, though under way for quite some time, has been gathering momentum and is perhaps best exemplified by the fact that the European Union has chosen to frame its 2020 poverty reduction target in terms of what is in effect a (rather crude) multidimensional measure of which low income is only one of three constituent elements.

Material deprivation as measured by a set of non-monetary deprivation indicators provides one of the additional elements in this measure, illustrating the new prominence which such deprivation measures have attained in poverty research and practice in OECD countries. This chapter has shown, using comparative data for the countries of the EU for illustration, how material deprivation indicators can be used to capture specific dimensions or aspects of deprivation, such as in basic everyday necessities, durables, housing, and the local neighbourhood. Those affected by these particular forms of deprivation can then to be identified, opening up new possibilities for teasing out the potentially distinctive causal processes at work. It also provides a basis for capturing the extent of multiple deprivation across these dimensions - how often these different forms or aspects of deprivation go together - which may be less than is often assumed. This type of analysis of specific aspects of deprivation and of multiple deprivation provides the base for new insights in making 
comparisons across countries, in tracking changes over time, and in framing policies to respond to the situation and needs of different groups.

We have indicated our agreement with the view that accepting that poverty is multidimensional does not automatically imply that one must opt for a multidimensional poverty index rather than focusing on multiple indicators. Combining indicators across a variety of dimensions into a 'headline' summary index then provides a basis for highlighting overall trends and differences across countries, though there is inevitably a loss of information in doing so. Aggregation choices, whether in relation to such indices or the utilisation of information relating to both income and deprivation by the analyst in relation to substantive as well as technical choices. Ultimately such decisions must be justified on the basis of the extent to which they increase our understanding of the underlying processes generating poverty and inform policy choices. Both the dimensions under consideration and the context in which they are employed, in terms of the level of development of the counties in which they are applied, are likely to have a crucial bearing on what can be considered appropriate. However, as we have argued, where it is deemed appropriate to construct a multidimensional index it is clearly desirable that it should be done on a transparent basis with clearly identified properties.

While it has been highly productive to date and is moving forward rapidly, this developing field faces a variety of obstacles. Both its conceptual and empirical underpinnings urgently require further development. Conceptually, there needs to be much greater clarity in specific applications as to precisely why a multidimensional approach is appropriate or helpful in answering the particular question or questions being posed. Empirically, various sophisticated methodological approaches are being developed and applied, but there is as yet little clear 
understanding or consensus about their advantages and disadvantages, and the settings in which one versus another would be more satisfactory or appropriate. The use of nonmonetary deprivation indicators and application of multidimensional measurement approaches to poverty measurement will not converge on a single 'best' approach, but a greater degree of methodological consensus is attainable and desirable. Similarly, at this point in time, the use of both consumption and income measures together may be the best course of action in order to fully examine the levels of and trends in poverty (Johnson 2004). Much has been learned to date from these approaches to studying poverty and exclusion, and their use is set to increase in the future. Here we have argued that exploiting the full potential of such approaches will depend not only on technical progress but on successfully locating their use within broader theoretical perspectives relating to the structured nature of disadvantage and inquality.

\section{References}

Atkinson. A, (2003). "Multidimensional deprivation; contrasting social welfare and counting approaches", Journal of Economic Inequality, 1: 51-65

Alkire, S and J. Foster, J. (2007). Counting and multidimensional poverty measurement, Oxford Poverty \& Human Development Initiative OPHI Working Paper 7 (2007)

Alkire, S and J. Foster, J. (2007). Counting and multidimensional poverty measurement, Oxford Poverty \& Human Development Initiative OPHI Working Paper 7 (2007)

Alkire, S and J. Foster, J. (2011a), "Understandings and Misunderstandings of Multidimensional Poverty Measurement", Journal of Economic Inequality, 9: 289-314.

Alkire, S and J. Foster (2011b), "Counting and Multidimensional Poverty", Journal of Public Economics, 95: 476-487

Alkire, A and M. E. Santos, M.E. (2010), Acute Multidimensional Poverty: A New Index for Developing Countries, Human Development Research Paper.

Alkire, A and S. Seth (2011), Decomposing India's MPI by State and Caste: Examples and Comparisons, OPHI Research in Progress 
Atkinson, A. B., B, Cantillon, B., E. Marlier, E., \& B. Nolan, B. (2002). Social Indicators: The EU and Social Inclusion. Oxford: Oxford University Press.

Bauman, K. (1998). Direct measures of poverty as indicators of economic need: Evidence from the survey of income and program participation. Population Division Technical Working Paper No. 30. Washington, DC: U.S. Census Bureau.

Bauman, K. (1999). Extended measures of well-being: Meeting basic needs. Current Population Reports P70-67. Washington, DC: U.S. Census Bureau.

Bauman, K. (2003). Extended measures of well-being: Living conditions in the United States. Current Population Reports P70-87. Washington, DC: U.S. Census Bureau.

Berthoud, R., Bryan, M., \& Bardasi, E. (2004). The dynamics of deprivation: The relationship between income and material deprivation over time. Research Report No. 219. London: Department for Work and Pensions.

Berthoud, R. and Bryan, M. (2011), 'Income. Deprivation and Poverty: A Longitudinal Analysis', Journal of Social Policy, 40, 11:135=156

Blank. R. (2008), "How to Improve Poverty Measurement in the United States", Journal of Policy Analysis and Management, 27: 233-54.

Bradshaw, J. and N. Finch (2003). "Overlaps in dimensions of poverty". Journal of Social Policy, 32: 513-525.

Boarini, R., \& M. Mira d'Ercole (2006). Measures of material deprivation in OECD countries. OECD Social Employment and Migration Working Papers No. 37. Paris: OECD.

Brewer, M, Goodman, A. and A. Leicester (2006), Household spending in Britain. What can it teach us about poverty? London, Institute for Fiscal Studies.

Bourgignon, F. and S. Chakravarty, S. (2003), "The Measurement of Multidimensional Poverty", Journal of Economic Inequality, 1: 25-49.

Breen, R., \& P. Moiso (2004). “Overestimated poverty mobility: Poverty dynamics corrected for measurement error”. Journal of Economic Inequality, 2: 171-191

Burchardt, T. J. Le Grand \& D. Piachaud, D. (2002). "Degrees of exclusion: Developing a dynamic, multidimensional measure". In J. Hills, J. Le Grand, \& D. Piachaud (Eds.), Understanding Social Exclusion, Oxford: Oxford University Press.

Cappellari, L. and S. P. Jenkins, S.P. (2007). "Summarising Multiple Deprivation Indicators" in J. Micklewright and S.P. Jenkins (eds). Poverty and Inequality: New Directions. Oxford: Oxford University Press.

Carle, A. C., K. J. Bauman and S. Short, S. (2009). "Assessing the Measurement and Structure of Material Hardship in the United States". Social Indicators Research 92:35-5. 
Cutler, D. M. and L. F. Katz (1991), "Macroeconomic performance and the disadvantaged", Brooklyn Papers on Economic Activity, 2: 1-14 (1991

Deaton, A. (2005), "Franco Modigliani and the Life Cycle Theory of Consumption", Banca Nazionale del Lavoro Quarterly Review, 58(233-234): 91-107 (June-Sep 2005).

Deaton, A. and M. Grosh (2000), "Consumption", in M. Grosh and P. Glewwe (eds.), Designing Household Survey Questionnaires for Developing Countries: Lessons from 15 Years of the Living Standards Measurement Study, New York: Oxford University Press.

Delhey \& Kohler (2006). "From Nationally Bounded to Pan-European Inequalities? On the importance of Foreign Countries as Reference Groups". European Sociological Review 22: $125-40$

Dewilde, K, (2004). "The multidimensional measurement of poverty in Belgium and Britain: A categorical approach”. Social Indicators Research 68, 331-369.

European Commission (2011), Employment and Social Developments in Europe 2001, DG Employment, Social Affairs and Equal Opportunities

Fahey, T. (2007). "The case for an EU-wide measure of poverty". European Sociological Review 23: 35-47.

Förster, M. F. (2005). "The European Social Space Revisited: Comparing Poverty in the Enlarged European Union”. Journal of Comparative Policy Analysis 7: 29-48.

Foster, J., J. Greer \& E. Thorbeck (1984). "A Class of Decomposable Poverty Measures2, Econometrica 52:761-766.

Friedman, M. (1957), A Theory of the Consumption Function, Princeton. Princeton University Press.

Fusco, A., Guio, A.-C., \& Marlier, E. (2010). Characterising the income poor and the materially deprived in European coun-tries. In A. B. Atkinson, \& E. Marlier (Eds.), Income and living conditions in Europe. Luxembourg: Publications Office of the European Union.

Goldthorpe, J. H. (2010) 'Analysing Inequality: A Critique of Two Recent Contributions from Economics \& Epidemiology’, European Sociological Review, 26 (6): 731-744

Gordon, D. (2002). Measuring Poverty and Social Exclusion in Britain: The Dynamics of Poverty Workshop, Central European University, Budapest, May 24-25.

Grusky, D. B., K. A. Weeden (2007). Measuring poverty: The case for a sociological approach. In: Kakawani, N., Silber, J. (Eds.), The Many Dimensions of Poverty. Palgrave Macmillan, Basingstoke.

Guio, A-C, Gordon, D. and Marlier, E. (2012), Measuring Material Deprivation in the EU: Indicators for the whole population and child specific indicators, Eurostat Methodological and Working Papers, Luxembourg, Publications Office of the European Union. 
Halleröd, B. (2006). "Sour grapes: Relative deprivation, adaptive preferences and the measurement of poverty". Journal of Social Policy, 35: 371-390.

Halleröd, B., D. Larsson, D., Gordon \& V. M. Ritakallio (2006). "Relative deprivation: a comparative analysis of Britain, Finland and Sweden". Journal of European Social Policy 16: 328-345.

Headey, B. (2008). "Poverty is Low Consumption and Low Wealth not Just Income", Social Indicators Research 89: 23-29

Hox, J. (2010). Multilevel analysis: Techniques and applications (2nd ed.). New York/Hove: Routledge

Jarvis, S. and S. P. Jenkins (1999). "Low income dynamics in the 1990s in Britain", Fiscal Studies 18: 123-142

Jencks, C., S. Mayer and J. Swingle (2004), "Can we fix the federal poverty measure so it provides reliable information about changes in children's living conditions?", Harvard University Faculty Research Working Paper Series, September 2004.

Jensen, J., M. Spittal, S. Crichton, S. Sathiyandra and V. Krishnan (2002), "Direct Measures of Living Standards: the New Zealand ELSI Scale", Ministry of Social Development, Wellington.

Johnson, D. S. (2004), "Measuring Consumption and Consumption Poverty: Possibilities and Issues", Prepared for "Reconsidering the Federal Poverty Measure" American Enterprise Institute.

Johnson, D. S., T. M. Smeeding, and B. N. Torrey (2005), "Economic inequality through the prisms of income and consumption”, Monthly Labor Review (April 2005).

Kakwani, N. \& J. Silber (Eds.), The Many Dimensions of Poverty. Basingstoke: Palgrave Macmillan.

Kenworthy, L. J. Epstein, J and D. Duerr (2011), "Generous social policy reduces material deprivation" in L. Kenworthy, Progress for the Poor, Oxford: Oxford University Press

Krueger, D. and F. Perri (2006), "Does Income Inequality Lead to Consumption Inequality? Evidence and Theory", Review of Economic Studies, 73: 163-193.

Levitas, R, C. Panatzis, E. Fahmy, D. Gordon, E. Lyod and D. Patios (2007). The MultiDimensional Analysis of Social Exclusion, Social Exclusion Unit, United Kingdom

Mayer, S. (1993). "Living conditions among the poor in four rich countries". Journal of Population Economics 6: 261-86.

Mayer, S. And Jencks, C. (1989), "Poverty and the distribution of material hardship". Journal of Human Resources, 24: 88-114 
Mayer, S. E. And C. Jencks (1993), "Recent Trends in Economic Inequality in the United States: Income vs. Expenditures vs. Material Well-Being," in D. Papadimitriou and E. Wolfe (eds.), Poverty and Prosperity in America at the Close of the Twentieth Century, London, Macmillan.

Meyer, B. D. and J. X. Sullivan (2003), Measuring the well-being of the poor using income and consumption, NBER Working Paper 9760.

Meyer, B. D. and J. X. Sullivan (2004), Consumption for the poor: what we know and what we can learn, Paper prepared for the ASPE-initiated workshop on Consumption among Low Income Families, Washington, November 5, 2004.

Meyer, B. D. and J. X. Sullivan (2007), Consumption and income poverty for those 65 and over, paper prepared for the $9^{\text {th }}$ Annual Joint Conference of the Retirement Research Consortium "Challenges and Solutions for Retirement Security", Washington, August 9-10, 2007.

Meyer, B. D. and J. X. Sullivan (2010), Five decades of consumption and income poverty, The Harris School of Public Policy Studies, University of Chicago, Working Paper 09.07.

Meyer, B. D. and J. X. Sullivan (2011), Consumption and income poverty over the business cycle, NBER Working Paper 16751 (January 2011).

Meyer, B. D. and J. X. Sullivan (2012), Measuring poverty: income, consumption and the new U.S. poverty measure, Feb 292012 ???

Modigliani, F. (1975), "The life-cycle hypothesis of saving twenty years later," in M. Parkin (ed.), Contemporary Issues in Economics, Manchester, Manchester University Press

Moisio, P. (2004). "A latent class application to the multidimensional measurement of poverty”. Quantity and Quality 38: 703-717.

Nolan, B. and C. T. Whelan (2007). "On the multidimensionality of poverty and social exclusion". In J. Micklewright, S. and Jenkins (Eds.), Poverty and Inequality: New Directions. Oxford: Oxford University Press.

Nolan, B. and C. T. Whelan (2011). Poverty and Deprivation in Europe, Oxford University Press, Oxford.

Noll, H.-H. (2007), Household consumption, household incomes and living standards. A review of related recent research activities, Paper prepared for the EQUALSOC-Project Household Consumption and Incomes in Comparative Perspective.

Perry, B. (2011). Material, Poverty, Hardship and Living Standards in New Zealand: A Brief Overview, $2^{\text {nd }}$ Peter Townsend Conference, Bristol

Pisati, M, C. T. Whelan, C. T., M. Lucchini and B. Maitre (2010). "Mapping Patterns of Multiple Deprivation Using Self Organising Maps: An Application to EU-SILC Data for Ireland". Social Science Research 39: 405-418 
Ravillion, M. (2011). 'On Multidimensional Indices of Poverty; Journal of Economic Inequality 9: 235-248

Ridge, T. (2002), Childhood Poverty and Social Exclusion, Bristol, Policy Press

Ringen, S. (1988). "Direct and indirect measures of poverty". Journal of Social Policy 17: 351-366.

Room, G. (1999). "Social exclusion, solidarity and the challenge of globalisation", International Journal of Social Welfare 8:166-74

Saunders, P, Y. Naidoo, and M. Griffits (2007). Towards New Indicators of Disadvantaged Deprivation and Exclusion in Australia, Social Policy Research Centre, University of New South Wales, Sydney

Saunders, P and A. Adelman (2006). "Income, Poverty, Deprivation and Exclusion: A Comparative Study of Australia and Britain", Journal of Social Policy, 35: 559-84

Scutella, B, Wilkins, R, and Kostenka, W, (2009), Poverty and Social Exclusion in Melbourne, Melbourne Institute Working Paper 26/09

Slesnick, D. T. (1991), "The Standard of Living in the United States", Review of Income and Wealth, 37(4): 363-386 (December 1991).

Slesnick, D. T. (1994), "Consumption, needs and inequality", International Economic Review, 35: 3.

Slesnick, D. T. (2001), Consumption and Social Welfare. Living Standards and their Distribution in the United States, Cambridge, Cambridge University Press.

Smeeding, T. M. (2009), "New comparative measures of income, material deprivation, and well-being", Journal of Policy Analysis and Management, 28(4): 745-752 (Autumn 2009).

Stiglitz, J.E., A. Sen, J.-P. Fitoussi, (2009). Report by the Commission on the Measurement of Economic Performance and Social Progress http://www.stiglitz-senfitoussi.fr/documents/rapport_anglais.pdf

Thorbecke, E. (2007). "Multidimensional poverty: Conceptual and measurement issues". In N. Kakawani \& J. Silber (Eds.), The Many Dimensions of Poverty. Basingstoke: Palgrave Macmillan.

Tomlinson, M. and Walker, R. (2009), Coping with Complexity: Child and Adult Poverty, London: Child Poverty Action Group

Tomlinson, M., A. Walker and G. Williams, G. (2008). "Measuring Poverty in Britain as a Multi-dimensional Concept, 1991 to 2003”. Journal of Social Policy 37: 597-620.

Townsend, P. (1979). Poverty in the United Kingdom. Harmondsworth: Penguin. 
Tsakloglou, P. and Papadopoulos, F. (2001) "Poverty, material deprivation and multidimensional disadvantage during four life stages: Evidence from the ECHP", in C. Heady, M. Barnes, J. Millar, S. Middleton, Tsakloglou and F. Papadopoulos (eds) Poverty and Social Exclusion in Europe, Edward Elgar, Cheltenham

Tsui (2002). "Multidimensional Poverty Indices”. Social Choice and Welfare 19: 69-93.

Whelan, C. T., R. Layte, R. and B. Maître (2004). "Understanding the mismatch between income poverty and deprivation: a dynamic comparative analysis". European Sociological Review 20:287-301.

Whelan, C. T. and B. Maître (2005). "Economic Vulnerability, Social Exclusion and Social Cohesion in an Enlarged European Community". International Journal of Comparative Sociology, 46:215-239

Whelan, C. T., \& B. Maître (2006). "Comparing poverty and deprivation dynamics: Issues of reliability and validity". Journal of Economic Inequality 4: 303-323..

Whelan, C. T. and Maitre, B. (2009). "Europeanization of inequality \& European reference groups". Journal of European Social Policy 19: 117-130.

Whelan, C. T. and B. Maître (2010a). "Welfare Regime and Social Class Variation in Poverty and Economic Vulnerability”. Journal of European Social Policy 20: 316-332

Whelan, C. T. and Maître, B. (2010b). “Comparing Poverty Indicators in an Enlarged EU', European Sociological Review”. 26: 713-73

Whelan, C. T., Watson. D. and Maître, B. (2010), Validating the ESeC Class Schema: Crosssectional and Dynamic Analysis of Income Poverty and Deprivation' in David Rose and Eric Harrison (Eds.), The European Socio-economic Classification, London, Routledge.

Whelan, C. T. and Maître, B. (forthcoming), "Understanding Material Deprivation: A Comparative European Analysis". Research in Social Stratification and Mobility, doi.1016/rssm.2012.05.001

Whelan, C. T. and Maître, B (2012a), 'Material Deprivation, Economic Stress and Reference Groups in Ireland an Analysis of EU-SILC, GINI Discussion Paper 36

Whelan, C. T. and Maître, B (2012b), 'Identifying Childhood Deprivation: How well do national indicators of Poverty and Social Exclusion in Ireland perform?', Economic and Social Review, 43, 251-272

Whelan, C. T., Nolan, B. and Maître, B (2012), 'Multidimensional Poverty in Europe: An Application of the Adjusted Head Count Ratio to EU-SILC 2009, GINI Discussion Paper 